\title{
Study on the Influence of Yi Handmade Embroidery and Fast Fashion Clothing Combined Development on the Achievements of Poverty Reduction in Liangshan Area
}

\author{
Zhiqiang Xu, Li Xu, Yu Fan, Xiaojun Guo, Jun Liu \\ Library of Xichang College, Xichang, China \\ Email: flytiger59@163.com
}

How to cite this paper: $\mathrm{Xu}, \mathrm{Z}$. Q., Xu, L., Fan, Y., Guo, X. J., \& Liu, J. (2021). Study on the Influence of Yi Handmade Embroidery and Fast Fashion Clothing Combined Development on the Achievements of Poverty Reduction in Liangshan Area. Open Journal of Social Sciences, 9, 407-417. https://doi.org/10.4236/jss.2021.96028

Received: May 14, 2021

Accepted: June 27, 2021

Published: June 30, 2021

Copyright $\odot 2021$ by author(s) and Scientific Research Publishing Inc. This work is licensed under the Creative Commons Attribution International License (CC BY 4.0).

http://creativecommons.org/licenses/by/4.0/

\begin{abstract}
Liangshan Yi Autonomous Prefecture, located in the southwest of Sichuan Province, is China's largest Yi ethnic community and one of the country's concentrated contiguous areas of deep poverty. On February 11, 2018, General Secretary Xi Jinping visited the poor people in the hinterland of Daliang Mountain and discussed with local officials and people on targeted poverty alleviation measures. In November 2020, the last seven state-level poverty-stricken counties in Liangshan Yi Autonomous Prefecture announced the elimination of poverty, thus eliminating all poverty-stricken counties in Sichuan Province. This is a historic moment for Liangshan Prefecture, a historic moment for Sichuan Province, and also a historic moment for China's poverty alleviation. In this paper, the combination of Yi's handmade embroidery and fast fashion clothing is of great practical significance to help Liangshan consolidate and expand the achievements of poverty alleviation.
\end{abstract}

\section{Keywords}

Liangshan Yi Nationality, Precision Poverty Alleviation, Hat Removal, Handmade Embroidery, Fashion Clothes

\section{Introduction}

As General Secretary Xi Jinping has pointed out, "Poverty alleviation is not the end, but the starting point for a new life and a new struggle." Now, standing at the starting point of new life and new struggle, Daliangshan people are full of confidence and look forward to embarking on a new journey of happy life and a better future. Therefore, now and for a long time to come, how to consolidate 
and expand the achievements of poverty alleviation by all means is a very realistic problem.

As a Chinese saying goes, "The boundless road is boundless, but the trade wind is blowing." Standing in rural poverty engines and revitalization of the two strategic transition, with two goals converge period in one hundred, the strong leadership of the communist party of China, the crucial foundation and successful experience out of poverty and the great spirit, the confidence in the new historical starting point to pursue a better life and spirit, we will be able to consolidate and expand good, the fruits of poverty and enable those who have lifted themselves out of poverty and those living in poverty alleviation areas to take new steps on the road to common prosperity (Li, 2014).

\subsection{Handmade Embroidery of Liangshan Yi Nationality}

Handmade embroidery of the Yi nationality in Liangshan is a national traditional handicraft with a long history, exquisite craftsmanship and high practicability. In the process of Liangshan crossing one thousand years, it embodies a strong traditional culture of the Yi nationality, which has been inherited and carried forward continuously.

In Liangshan, Yi embroidery has a wide base of masses. There is a wisecrack that "Yi strong men can drink more and Yi beautiful women are better than hand embroidery", which reflects from the side that Yi embroidery is a basic skill commonly mastered by Yi women in Liangshan. Yi hand embroidery has a long history and exquisite patterns. In recent years, Yi embroidery has gradually developed into a new characteristic industry for the masses of Liangshan Prefecture, especially Yi women, to get rid of poverty and become rich. The majority of Yi women can create wealth and weave a happy life with their industrious and dexterous hands without leaving their homes.

\subsection{Research on Fast Fashion at Home and Abroad}

Based on the aesthetic characteristics of Liangshan Yi costumes, this paper intends to explore concise and modern Yi costume design in depth in combination with modern fashion aesthetic standards, seeking the collision between tradition and fashion, and through the "fast fashion" mode of e-commerce channels, so that Yi costume culture can go to a larger market and be accepted and loved by more people. Therefore, the combination of Yi's handmade embroidery and e-commerce "fast fashion" fashion brands is of great practical significance to help Yi women consolidate and expand the achievements of poverty alleviation (Gao, 2019).

In recent years, maintain fast and stable economic growth in China, the residents' income and consumption level under the background of rapid increase, the booming Chinese clothing consumption market, many international famous "fast fashion" clothing retail brands, such as Spain's ZARA, C\&A, H\&M, the Netherlands, Sweden and Japan's UNIQLO, etc., have entered the Chinese market, It not only occupies China's offline market, but also competes fiercely with 
China's local clothing brands on online e-commerce platforms. The concept of "fast fashion" has only emerged in recent years, and it also brings Chinese consumers a different shopping experience. In China, a number of "fast fashion" brands have also been developed (Liao \& Mou, 2020).

1) "Fast fashion" refers to a marketing mode, mainly in the clothing industry and originated in Europe and the United States. It is characterized by fast product renewal, low price, fashionable and novel styles, which are popular among modern youth, especially professional white-collar workers, and swept the world. The brand "ZARA" belonging to the Spanish Inditex Group is the earliest "fast fashion" brand, and the "GAP" of the United States, the "H\&M" of Switzerland, and the "U-Niqlo" of Japan (Uniqlo) are representative fast fashion brands. With the development of China's economy, more and more foreign clothing brands have settled in major cities in China, leading the trend of "fast fashion" in China. During this period, a number of domestic fashion brands have transformed and grown rapidly and entered the ranks of "fast fashion", such as "Meters-Bonwe", "Semar", "Mix-Box" and so on.

Fast fashion brands are mainly targeted at middle and low-end consumer groups. Those consumers who are highly sensitive to fashion and do not have the ability to consume international high-end products are the loyal customers of these fast fashion brands. They usually judge fashion trends through information such as international fashion weeks and new product launches of international brands, and quickly design and produce the latest fashion clothes, which are put into the market and into the hands of the public, and make use of the creativity and popularity of international brands to create a buzz for themselves. They update their products very quickly, like Zara, every two to three weeks, and they never repeat. Consumers can always find the most fashionable clothes with designs similar to the luxury brands of the season, in line with the popular aesthetic, and at low prices, so sales of fast fashion brands have never been a concern for companies. The Zara brand is not the largest number of Inditex stores, but it accounts for $60 \%$ of the group's sales.

With the development of global economic integration, cultural differences and aesthetic orientation in different parts of the world are gradually converging, and the slogan of "fashion without borders" is becoming louder and louder, which promotes the accelerated expansion of fast fashion brand market and spreads all over the world in just over 20 years. Spanish brand Zara, a pioneer of fast fashion, has developed into one of the most successful brands in the world, with nearly 1900 stores in 87 countries by the end of 2013. And the development of other fast fashion brands is more fierce, has the potential to surpass. With the advantage that its price is $30 \%$ lower than Zara's, H\&M has more than 3000 stores, and its annual sales volume has ranked first in the industry for several times. However, China, the world's largest emerging market, has huge market potential due to its large population, which attracts major fashion brands from all over the world, including major fast fashion brands. Since the first Uniqlo store opened in Shanghai in 2002, many fashion brands have landed in major ci- 
ties in China and gradually spread to second-and third-tier cities. The total number of stores of top ten international fast fashion brands in China has exceeded 1900. One of the secrets of the rapid development of foreign fast fashion clothing brands is that they can accurately grasp the fashion pulse and occupy the market first. The product update speed is so fast that it can be used to add the popular elements into the clothes and put them on the shelves in about 14 days. Compared with foreign fast fashion brands, domestic brands have a long production cycle and slow renewal. In recent years, China's local clothing brands have developed slowly, but many foreign brands have developed rapidly after entering the Chinese market and occupied a lot of market shares. A series of fast fashion brands, such as $\mathrm{H} \& \mathrm{M}$, have captured a large number of consumers with their fashion, cheap price and other advantages. Therefore, in the future development of domestic local clothing brands, they should try their best to shorten the online cycle, accelerate the updating speed, and conduct fast and effective supply chain management. Only in this way can they grab the market share first.

2) According to statistics, during the 13th Five-Year Plan period, the number of Internet users in China increased from 688 million to 989 million, an increase of $43.7 \%$ in five years. By December 2020, China had 989 million Internet users, and the Internet penetration rate had reached 70.4 percent. With the development of the Internet, users' values are upgraded, bringing about changes in users' economic behavior. The first stage is "people search information", that is, users search information; the second stage is the development of "information seeking", namely UGC (User Generated Content). As to promote the personalized features of web 2.0 concepts, from the original give priority to in order to download and upload, pay equal attention to the interaction of the user, the user is not only the content of your visitors, is also the creator of the web content, thus showing "emotional connection, identity, birds of a feather flock together, birds of a feather flock together". Correspondingly, network e-commerce has also moved from the dominant direction of "from things to people" based on commodity price driven 1.0 era to the "from people to things" based on trust relationship recommended $2.0 \mathrm{era}$. In the 2.0 era when UGC has reached a scale of 22 million and generated 30 hours of online content per minute, the marketing of apparel businesses, especially e-commerce apparel businesses, will take on a new look, that is, content + e-commerce $=$ brand + sales, including content output, form development, channel expansion, operation realization, promotion and communication, etc. It presents the operational characteristics of "socialization, fanization and content".

\subsection{The Unique Application Value of This Paper}

So far, there are few fashion brands with ethnic elements as the dominant design among Chinese national fashion brands, and the well-known $\mathrm{Yi}$ fashion brands are even less. Therefore, the establishment of a market-oriented fashion brand combining Yi embroidery technology is one of the important goals of this paper. Liangshan Prefecture has all kinds of minority style clothing 
brands, most of which are mainly presented with local ethnic characteristics. However, there are few changes in clothing types, few style categories, low fashion degree and low innovation ability, which are missing a piece in the fashion brand market.

The inheritance, protection, development and innovation of Liangshan Yi costumes are not only of great and far-reaching significance for displaying the new image of the Yi people, enhancing the popularity and influence of the Yi culture, and enhancing national cohesion and pride, but also conducive to the Yi costume cultural brand entering a broader market. However, from the perspective of integrating into contemporary life, it is an indisputable fact that some of the traditional costumes of Liangshan Yi nationality, which are thick, heavy and large, are not in harmony with the lifestyle and social rhythm of modern people and appear outdated.

In today's diversified modern aesthetics and public needs, innovative design and technological upgrading are the driving force for the sustainable development of Yi clothing industry. Modern society is a commercial society, any product must carry out a unified planning, design, publicity and marketing; this is in line with the law of market operation. For a long time, Yi clothing has been produced by cottage industry workshops, which are sold by themselves or on commission. There is almost no participation of trade associations, chain operation, e-commerce and other modern sales means, and no effective marketing system and network platform of Yi clothing cultural industry has been formed. The apparel industry of Yi nationality has a small scale, lacks leading enterprises with strong driving force and influence, and lacks strong market competitiveness, low economic benefits and prominent brand effect, so it is difficult to adapt to the needs of market development.

Yi hand embroidery and electrical business fast fashion clothing is the combination of development, in protecting the integrity of the traditional Yi embroidery and core skills on the basis of, by improving the material design, improvement, improvement of production, improve quality, so as to improve the traditional Yi embroidery apparel market competitiveness, and the development level of the Yi nationality clothing culture will go much more market, was accepted and loved by more people. Sales of Yi embroidery fast fashion clothing through online and offline channels, promotion of Yi embroidery fast fashion clothing products and brand promotion through exhibitions, competitions, exhibitions and competitions. Through the establishment of an Internet promotion platform, relevant products are recommended to attract investors to invest in Yi embroidery fast fashion clothing related projects. These are of great practical significance to consolidate and expand the achievements of poverty alleviation in Liangshan.

\section{Research Content}

\subsection{Research Objects and Objectives}

This paper intends to study the combined development of Yi's manual embroi- 
dery and e-commerce fast fashion clothing. The goal is to help the development of Liangshan Yi characteristic industries and make contributions to consolidate and expand the hard-won achievements of poverty alleviation.

\subsection{Key and Difficult Points in This Paper}

Study and comb out the traditional cultural connotation of Liangshan Yi embroidery, combine with the concept of clothing design, and deeply explore the combined value of Liangshan Yi embroidery and fashion clothing according to the fashion market.

Liangshan "Yi embroidery" has a long history, exquisite skills and high practicability. In the process of Liangshan's one thousand years, "Yi embroidery" embodies a strong traditional culture of the Yi nationality, and its craft has been inherited and carried forward with the development of history.

Liangshan Yi nationality area covers a vast territory and is one of the main settlements of Yi people. Due to living customs, natural environment, historical development and other factors, the Yi culture has its own characteristics, "Yi embroidery" is the same. Under the premise of fully understanding the cultural connotation of Yi nationality, designers of clothing brands apply "Yi embroidery" to their designs, which can better spread the enthusiastic, thriving and trend-leading regional image of Liangshan Yi nationality area.

Yi hand embroidery has exquisite patterns and a long history. As an important advantageous characteristic industry in Liangshan Prefecture, it has the advantages of congenital products and acquired platform for the development of e-commerce. Handmade embroidery of Liangshan Yi nationality, the color symbol of this nation not only carries the ancient culture, but also is a part of the cultural soft power of minority areas today (Zheng \& Zhou, 2016).

The Yi embroidery on the costumes of the Yi nationality in Liangshan, as the typical representative of the costumes in the "Yi Nuo" dialect area of Liangshan Prefecture, has rich and colorful patterns, and the common patterns include animal patterns, plant patterns, geometric patterns, and utensils patterns.

The common animal patterns are crab foot pattern, sheep horn pattern, cow horn pattern, horse tooth pattern, cow eye pattern, chicken comb pattern, etc., mostly based on cattle and sheep patterns, and these patterns are mostly drawn from the production and life of the Yi people, cattle and sheep are the main poultry. It is an expression of the life of the nomadic ancestors and represents happiness and wealth.

The root, stem, leaf and fruit patterns of various plants and crops, such as fern striata and sun pattern, are common plant patterns. Fern striata pattern and sun pattern are common patterns of Meigu Yi costume. One of the oldest plants in the world, the fern striata was an important source of food collected by the ancestors of the Yi people, who often relied on it to survive famines and called it "lifesaver grass". The sun pattern shows the worship of the Yi people to the sun.

Among the geometric patterns, the sun and moon, wave, whirlpool, rainbow and star patterns are common, which are used to express the worship of celestial 
bodies and the worship and awe of nature, and to pray for and avoid disasters in nature, so as to bless the Yi people to have a safe year after year, free from natural and man-made disasters, and good harvests in agriculture and animal husbandry.

The patterns of utensils, such as flaming sickle pattern, Guozhuang pattern and stone steps pattern, are common patterns in Yi's embroidery. These patterns are commonly used in the daily life of the Yi people. For example, the flaming torch is an important fire-making tool in Meigu region, while the toast seal is a symbol of power, nobility and wealth.

Embroidery has always been a common decorative technique for high-grade clothing since ancient times. Chinese traditional cheongsam, Japanese kimono and European wedding dress have been extensively used in this craft.

In high fashion, the most concentrated use of embroidery technology is the cuff, collar, chest, trousers, etc. Colored embroidery is the most commonly used technique in traditional Chinese cheongsam. Colored silk threads are used to produce rich color changes through overlapping, juxtaposition and interlace, making the flowers on the dress lifelike, just like ink painting.

The traditional embroidery craft is varied, which brings a kind of traditional luxury and beauty to the clothes and reflects a kind of elegance. Even a small embroidered cotton handkerchief contains delicacy, which has been the conventional application direction of embroidery craft for a long time. So far in 2014, there are few fashion brands with ethnic elements as the dominant design among China's national fashion brands, and the well-known Yi fashion brands are even more empty. Therefore, the creation of market-oriented fashion brands combining Yi embroidery technology is also one of our research objects and main goals.

\subsection{Feasibility of This Study "Yi Embroidery"}

Is the main component of Liangshan Yi costumes, and mastering the skills of "Yi embroidery" has become a magic weapon for Yi women to get rid of poverty and become rich. Among the registered poverty-stricken households in Liangshan Prefecture, poverty-stricken Yi women account for $57 \%$ of the poverty-stricken population in the prefecture, which is $10.5 \%$ higher than that in the whole country. For this special group, the causes of poverty are complex, the depth of poverty is extraordinary, the difficulty of poverty is great, and the risk of returning to poverty is high. This special group is not only the fortress of the achievements of poverty alleviation in Liangshan Prefecture, but also one of the keys to consolidate and expand the achievements of poverty alleviation.

In Liangshan, "Yi Embroidery" has a wide base of masses. There is a wisecrack that "Yi strong men can drink more and Yi beautiful women are better than hand embroidery", which also reflects from the side that "Yi Embroidery" in Liangshan is a basic skill commonly mastered by Yi women. In recent years, as the Women's Federation of Liangshan Prefecture has implemented the Opinions of the All-China Women's Federation on "Women's Poverty Reduction Action" 
in the Fight Against Poverty, "Yi embroidery" has gradually developed into a new characteristic industry for the people of Liangshan Prefecture, especially Yi women, to get rid of poverty and get rich. The majority of Yi women can create wealth and weave a happy life with their industrious and dexterous hands without leaving their homes.

Fast fashion is a sales mode in which fashion clothing enterprises quickly respond to the fashion design on the runway and produce products closely to the latest fashion trend, which are sold to the stores at low prices and mainly targeted at mainstream consumers. Liangshan Prefecture has all kinds of minority style clothing brands, most of which are mainly presented with local ethnic characteristics. However, there are few changes in clothing types, few style categories, low fashion degree and low innovation ability, which are missing a piece in the fashion brand market.

With the continuous popularization of the Internet in China, the development of the Internet and mobile Internet in China has gradually matured, and even unlimited traffic has begun to appear. While the threshold of using the Internet is constantly lowered, Internet products are increasingly filling our lives. At the same time, mobile terminal users continue to increase, even becoming twice as many as PC terminal users, and people's demand for simplicity, fast and interesting also increases. From fragmented reading to short video watching, China's "We Media" also develops rapidly.

To fully promote "embroidered Niang" Liangshan prefecture skill level and innovation ability, consolidate hand embroidery and better develop Liangshan out of poverty, the combination of the paper will hand embroidery products domestic and electrical business channels and cutting-edge fashion design and web celebrity incubator combination, make fast fashion clothing brand new hatch pattern, make Yi embroidery Internet fashion goods, it provides a good market environment and creation conditions for the Yi Xiuniang, helps the Xiuniang transform the products into commodities and enter the market as soon as possible, helps the emerging Yi elements and Yi style fast fashion clothing brands grow up and form a scale rapidly, and helps some families in poor Yi areas to live a happy life.

\subsection{Research Plan of This Paper}

The research time of this paper is about 3 - 4 years. Firstly, the person in charge of this paper will take the lead to further deepen the research ideas and research plans. Secondly, organize members of this paper to discuss and implement the division of labor and cooperation related to this paper, such as Yi embroidery and fast fashion clothing data collection, information economy research, talent training and study, product promotion, and paper writing. It is expected that through the joint efforts and collective tackling of the members of this paper, we will strive to produce high level, high quality and landmark research results. To be specific, the following research works will be promoted step by step by time. 
1) Carry out research and comb to excavate the value of Yi embroidery. Dig deeply into the connotation of traditional Yi embroidery in Liangshan Prefecture, comb out its historical context and technical characteristics, and provide a solid foundation for the creative transformation and innovative development of traditional Yi embroidery products to adapt to modern life. The research results shall be shared with relevant enterprises and practitioners.

2) Build an innovation platform and gather various forces. Explore the innovative mode of integrating scientific research, design, management and sales, build an e-commerce platform combining Yi embroidery and fast fashion, and provide strong support for the industrial development combining traditional Yi embroidery and fast fashion.

3) Carry out skill training to improve the level of inheritors. Training and study should be carried out to cultivate multi-level professionals for the e-commerce industry that combines Yi embroidery clothing and fast fashion, and support and help the research and recreation of the local Yi embroidery clothing industry. It provides a platform of observation, study, research, training and foreign exchange for the craftsmen of Yi embroidery costumes in Liangshan Prefecture.

4) Strengthen creative design and improve product quality. On the basis of protecting the authenticity and core skills of traditional Yi embroidery, we should improve materials, design, production and quality, so as to enhance the development level and market competitiveness of traditional Yi embroidery costumes.

5) Organize sales promotion and cultivate local brands. Sales of Yi embroidery fast fashion clothing through online and offline channels, promotion of Yi embroidery fast fashion clothing products and brand promotion through exhibitions, competitions, exhibitions and competitions. Establish an Internet promotion platform to promote relevant products and attract investors to invest in Yi embroidery fast fashion clothing related projects.

\section{Innovation of This Paper}

As a treasure in the treasure house of Chinese culture, the traditional hand embroidery of the Yi nationality in Liangshan is an ancient civilization and cultural art deposited from the tide of history. Combining the hand embroidery art of the Yi nationality with modern fashion clothing has an important influence on inheriting and developing the traditional Chinese culture. Throughout Yi hand embroidery craft and combined with the problems about the design of clothing, if you want to more thoroughly improve the quality of hand embroidery clothing design, hand embroidered and costume design talents and skilled personnel electric business operation personnel training mode should adopt combination, Xichang college to Liangshan local colleges and universities, the domestic top clothing design company conducted in-depth exchanges and cooperation.

1) For the existing embroidery women, clothing designers and e-commerce 
specialists, it is necessary to not only carry out artistic aesthetic edification, but also teach the understanding of hand embroidery to the traditional artistic themes.

2) In hand embroidery skills training, hire a costume design professional to fashion, professor of practical knowledge, from clothing to learn Angle, namely the clothing styles, fabrics, design, and other aspects systematically analysis technology in the clothing of Liangshan hand embroider on the use of market prospect and pay attention to the problem, make the embroidered Niang in the face of fashion design products, able to deeply understand the design connotation, And according to the design concept of technical work.

3) At present, most of the hand-embroidered clothing works and handicrafts of the Yi nationality exist in the market, and their sales mode is mainly brick-and-mortar stores. In the era of diversified development of economic market, this traditional sales mode urgently needs to be changed. With the help of the network business platform, to create Liangshan Yi embroidery style of fashion exclusive flagship store. In today's social market sales, e-commerce increasingly plays an important role in sales channels. Liangshan Yi embroidery fashion will make use of this sales channel with good market prospects to carry out all-weather online sales (Li \& Kuang, 2019).

\section{Expected Results of This Paper}

By implementing Yi embroidery combined with fast fashion clothing brand, it realizes with $\mathrm{Yi}$ ethnic characteristics of the Internet media electrical goods brand incubation, supports Yi embroidery Niang employment, achieves a variety of fashion style clothing brand with Yi embroidery elements, and creates more than 5 national fashion brands with the combination of different styles of Liangshan Yi embroidery region characteristic. More than 100 web celebrity college students who are self-employed and more than $100 \mathrm{Yi}$ embroidery women who are capable of hand embroidery in Liangshan have been solved. The final results of the project are finished in terms of product photos, design patents and paper forms.

This paper introduced the concept of incubator, with the guide of e-commercial thinking, providing fashion design research and development technology, clothing production services, the Internet business selling technical guidance and training, clothing design, clothing plate proofing, hand embroidery, garment production, the red live sales, from the media, such as office space, at the same time, it has the system of training and consulting, policies, financing, legal and marketing support, sharing space, sharing services, incubating enterprises, incubator managers, and preferential policies to support enterprises. It provides a good entrepreneurial environment and conditions for incubating local original fashion brands with ethnic characteristics, and helps designers to form their inventions and achievements into commodities and enter the market as soon as possible. At the same time, it combines the national handicrafts and fashion de- 
sign of Liangshan Yi embroidery with the concept of fast fashion. The platform mode is adopted to cultivate local e-commerce fashion fast fashion brands with local characteristics of Liangshan Yi nationality.

In view of the pre-investigation of the integration of all kinds of resources, the project can be launched at a small cost to integrate all kinds of resources. Integration of domestic and foreign clothing designer, Liangshan Yi Niang, top flow web celebrity resources, provides comprehensive services, development, production and domestic top fashion design company cooperation. With the cooperation of Liangshan local embroidery handicraft company and domestic top web celebrity media company, participating in Liangshan intangible creative competition, it builds Internet ecological clothing development and production of sales of the closed loop.

Under the premise of the mainstream upgrading of the young and fashionable clothing industry, mobile social media is taken as the new consumption engine, and the cultural creativity with the national characteristics of Yi's handmade embroidery is endowed with a brand new connotation of fashion. At the same time, through the e-commerce "We Media" form of operation, it provides personalized customized services, with the sales end of the rapid response and feedback.

We will seize the opportunity of new technology, new mode and new business form, integrate the Yi nationality's handmade embroidery into the current market environment more widely and deeply, and carry forward the national characteristic culture.

\section{Conflicts of Interest}

The authors declare no conflicts of interest regarding the publication of this paper.

\section{References}

Gao, H. (2019). Research on the Current Situation and Countermeasures of the Communication of Yi Culture WeChat Public Account. News and Communication, January Second Monthly Issue (Total Issue 83).

Li, J. (2014). Analysis of Handmade Embroidery of Yi Nationality and Its Present Situation. Northern Literature, No. 1, 180.

Li, J., \& Kuang, R. (2019). Research on the Design of Cultural Creative Products Based on the Protection of the Immaterial Cultural Heritage of the Yi Nationality-Taking the Traditional Embroidery Products of Ganluo Yi Nationality in Liangshan Prefecture as an Example. Research on Heritages and Preservation, 4, 91-94.

Liao, Y., \& Mou, Y. (2020). On Digital Protection of Liangshan Yi Embroidery. Cultural Industry, No. 6.

Zheng, Q., \& Zhou, F. (2016). Development Prospects of Yi Handmade Embroidery under the New Economic Policy. Global Market Information Guide, No. 33, 12-13. 